\title{
Application of Grey Forecasting Model Based on Improved Residual Correction in the Cost Estimation of University Education
}

\author{
http://dx.doi.org/10.3991/ijet.v10i8.5215 \\ Chao Ge, Jiaqi Xie \\ Agricultural University of Hebei Baoding, Hebei, China
}

\begin{abstract}
The forecast of the cost of education in university is conducive to strengthening the management of the cost of education, mining the potential of reducing the cost, improving the management level and improving the use efficiency of the funds. Through accounting and forecasting of the cost of education in university, we can make the school to plan the cost and quota index according to its own practical needs, so as to improve the financial system and cost management system of university education. This will enable the university to carry out the correct decision-making, and provide support for the preparation of financial budget and long-term planning. At present, there are some defects in existing method of the university education cost prediction. The unitary regression method is very difficult to effectively remove the noise value in the fitting. Artificial neural network model is applied to predict the big data. Although the traditional gray forecasting model has a good prediction effect with the less data and poor information, the model still has the disadvantage that the background value is not smooth enough. In order to solve the above problems, this paper proposes an adaptive residual correction method based on grey system theory, and improves the grey forecasting model. This method can effectively remove the noise in the original data sequence, and it can be used to predict the cost of university education in China.
\end{abstract}

Index Terms-Gray Model, Adaptive Residuals, University Education, Cost Estimation

\section{INTRODUCTION}

The cost of university education is not only an important basis for the government to set up the fees and charges for universities, but also the important content of the financial cost management in university. Strengthening the education cost accounting in university has become the focus of the government, universities and the public. The forecast of the cost of education in university is conducive to strengthening the management of the cost of education, mining the potential of reducing the cost, improving the management level and improving the use efficiency of the funds. Through accounting and forecasting of the cost of education in university, we can make the school to plan the cost and quota index according to its own practical needs, so as to improve the financial system and university education cost management system. This will enable the university to carry out the correct decisionmaking, and provide support for the preparation of financial budget and long-term planning.

As one of the earliest scholars in the study of educational economics, J.vaizey in his books "education costs" mentioned the "cost of education" for the first time. In this book, he analyzed the changes in the UK education funding in the early twentieth century, and considered that the cost of education was the education fund [1]. W.Schulte proposed the concept of cost of all the elements of Education in the "economic value of education ". He believed that the cost of all the elements of education were composed of two parts, which were the cost of education services and the opportunity cost of the students to go to school [2]. E.Cohn was not directly given the definition of the cost of education. He used a list to express the contents of the educational cost. He believed that education costs can be divided into two categories, which were direct cost and indirect cost [3]. Yan Dawu and Wang Geng thought that education cost was the sum of the value form of the physical labor and living labor in the process of education [4-5]. Wang Shanmai believed that the education cost was the value of the educational resources which were used to cultivate the students [6]. Yuan Liansheng divided the concept of higher education into two levels. The first level was the concept of the cost of measurement and classification of educational resources. The second level was based on the analysis of educational decision and educational cost [7]. Since 1980s, domestic and foreign scholars had carried on the research to the measurement method of university [8-15]. Generally speaking, the measurement method of education cost can be divided into two categories, which were the mathematical statistics method and the accounting method. Mathematical statistics method is the method of obtaining the cost of education through data processing. The source of the data was obtained from the existing educational funds and sample surveys. At present, most of the educational cost data at the school level were calculated by this method.

This paper proposes an adaptive residual correction method based on grey system theory, and improves the grey forecasting model. This method can effectively remove the noise in the original data sequence, and it can be used to predict the cost of university education in China. The structure of this paper is as follows. We introduce the cost of university education in the second section; in the section 3 , the related work of the traditional grey model is given; in the section 4 and 5, we construct the modify GM $(1,1)$ model and use the model to forecast the cost of university education in China; the last two sections are conclusions and references.

\section{ClassificAtion Of EdUCATIONAL COST IN UNIVERSITY}

According to the nature and purpose of the cost of education in university, it can be divided into material cost 
and labor cost. Material cost is a part of the funds for the college educational activities in a certain period, and the labor cost is a part of the consumption of living labor in higher education in a certain period.

According to the different relations of the educational cost of the university, it can be divided into direct cost and indirect cost. Direct cost is the cost of direct use in teaching, public assistance teaching and student assistance. It is the cost to achieve the goal of university education, and the indirect cost is the cost of indirect use in the teaching target, such as the administration fee, the teaching management fee, etc...

In accordance with the scope of university education cost management, it can be divided into the total cost of college education and education cost of each branch. The total cost of the university is the sum of all kinds of expenses that the school uses it to train the students, and the education cost of each branch is the consumption cost in running the schools.

In this paper, we follow the second classification methods, as shown in Table 1.

TABLE I.

TYPE SIZES FOR CAMERA-READY PAPERS

\begin{tabular}{|c|c|c|c|}
\hline \multirow{4}{*}{$\begin{array}{l}\text { Education } \\
\text { cost }\end{array}$} & \multirow{3}{*}{$\begin{array}{l}\text { Direct } \\
\text { cost }\end{array}$} & \multirow{2}{*}{$\begin{array}{c}\text { Social } \\
\text { direct cost }\end{array}$} & $\begin{array}{l}\text { Education expenditure of the } \\
\text { state budget }\end{array}$ \\
\hline & & & $\begin{array}{l}\text { Extra budgetary funds for } \\
\text { schools' income }\end{array}$ \\
\hline & & $\begin{array}{l}\text { Personal } \\
\text { direct cost }\end{array}$ & $\begin{array}{l}\text { The cost of student living, such } \\
\text { as the basic necessities of life }\end{array}$ \\
\hline & $\begin{array}{l}\text { Indirect } \\
\text { cost }\end{array}$ & & $\begin{array}{l}\text { The opportunity cost, such as tax } \\
\text { costs, fixed assets depreciation } \\
\text { costs }\end{array}$ \\
\hline
\end{tabular}

\section{RELATED WORK}

Grey model is the basic model of grey system theory, and it is also the basis of grey control theory. It is based on the gray model and the model is built by differential fitting method. Next, we give the basic algorithm of the gray model.

Firstly, we set the non-negative sequence is

$$
x^{(0)}=\left\{x^{(0)}(1), x^{(0)}(2), \mathrm{L}, x^{(0)}(n)\right\}
$$

Then, the first-order accumulated generating operation sequence is

$$
\begin{aligned}
x^{(1)}=\left\{x^{(1)}(1), x^{(1)}(2), \mathrm{L}, x^{(1)}(n)\right\} \\
\text { Which, } \\
x^{(1)}(k)=\sum_{i=1}^{k} x^{(0)}(i) .
\end{aligned}
$$

Let the background value series be

$$
\begin{gathered}
z^{(1)}(\mathrm{k})=\frac{1}{2}\left[x^{(1)}(k-1)+x^{(1)}(k)\right] \\
k=2,3, \mathrm{~L}, \mathrm{n}
\end{gathered}
$$

The grey differential equation is constructed with $x^{(1)}$ by

$$
\text { Eq. (1) }
$$

$$
\frac{d x^{(1)}}{d t}+a x^{(1)}=u
$$

Which $a$ is called development coefficient. $u$ is called grey action variable.

The discrete form of Eq. (4) is

$$
x^{(0)}(\mathrm{k})+a z^{(1)}(\mathrm{k})=u
$$

Put parameters into grey differential equation (4), the solution is

$$
x^{(1)}(t)=\left[x^{(1)}(1)-\frac{\hat{u}}{\hat{a}}\right] e^{-\hat{a} t}+\frac{\hat{u}}{\hat{a}}
$$

The discrete form of solution is

$$
\begin{aligned}
x^{(1)}(k+1) & =\left[x^{(0)}(1)-\frac{\hat{u}}{\hat{a}}\right] e^{-\hat{a} k}+\frac{\hat{u}}{\hat{a}} \\
k & =1,2, \mathrm{~L}
\end{aligned}
$$

Restore the first-order accumulated generating operation, we will get the prediction form.

$$
\begin{gathered}
\hat{x}^{(0)}(k+1)=\hat{x}^{(1)}(k+1)-\hat{x}^{(1)}(k)=\left(1-e^{\hat{a}}\right)\left(x^{(0)}(1)-\frac{\hat{u}}{\hat{a}}\right) e^{-\hat{a} k}(8) \\
k=1,2, \mathrm{~L}
\end{gathered}
$$

In the gray model, the gray plane is called the shadow area between the upper and lower bounds of the predicted value. The size of the gray plane is determined by the gray area of the forecast values for each future time. From Figure 1 we can see, with the passage of time, the grey interval of forecast value is more and more big. Due to the extrapolation of time, the system is gradually distorted. In order to avoid this problem, we put forward a series methods to adjust and modify the gray system theory, thus improving the accuracy of the model.

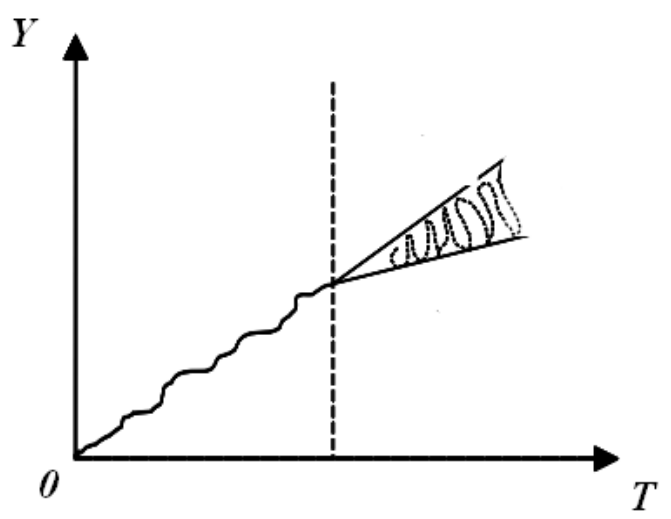

Figure 1. The diagram of Grey interval

\section{The Modify GM $(1,1)$ Model}

Although the gray system theory is not required to be so much information, it can use a small number of discrete, chaotic data to find their inherent laws. So, we will achieve the purpose of whitening the gray information. However, the GM $(1,1)$ model has a great impact on the original data, and the number of the sequence generated by the accumulation will have a great impact on the development of the model. So, it can weaken the regularity of the development of the system, we cannot get the desired results. Therefore, we have to improve the GM $(1,1)$ model with the residual error correction method.

The sequence of the original residuals is

$$
\varepsilon^{0}=\left(\varepsilon^{1}, \varepsilon^{2}, \mathrm{~L}, \varepsilon^{n}\right) .
$$

Among them, the $\varepsilon^{0}(k)=x^{(1)}(k)-\hat{x}^{(1)}(k)$ is the residuals sequence of $X^{(1)}$. 
If $k_{0}$ satisfies the following conditions.

(1) $\forall k \geq k_{0}, \varepsilon^{0}(k)$ 's symbol is the same;

(2) $n-k_{0} \geq \frac{n}{2}$, the $\left(\left|\varepsilon^{0} k_{0}\right|,\left|\varepsilon^{0}\left(k_{0}+0\right)\right|, \mathrm{L},\left|\varepsilon^{0}(n)\right|\right)$ is known as the residuals tail that can be used to build a model.

We use $\varepsilon^{0}$ to build the GM $(1,1)$ mode, find out its parameter column vector that is $A=\left[\begin{array}{l}a_{\varepsilon} \\ u_{\varepsilon}\end{array}\right]$, and calculate the fitting value of $\hat{\varepsilon}^{0}(k+1)$.

$$
\hat{\varepsilon}^{0}(k+1)=\left(-a_{\varepsilon}\right)\left(\varepsilon^{0}\left(k_{0}\right)-\frac{u_{\varepsilon}}{a_{\varepsilon}}\right) e^{-a_{\varepsilon}\left(k-k_{0}\right)}
$$

The formula (7) is amended as follows:

$$
\hat{x}_{1}^{(1)}(k+1)=\left\{\begin{array}{cc}
x_{1}^{(1)}(0)-\frac{1}{a} \sum_{i=2}^{n} u_{i} x_{i}^{(1)}(k+1) e^{-a k}+\frac{1}{a} \sum_{i=2}^{n} u_{i} x_{i}^{(1)}(k+1) & k<k_{0} \\
x_{1}^{(1)}(0)-\frac{1}{a} \sum_{i=2}^{n} u_{i} x_{i}^{(1)}(k+1) e^{-a k}+\frac{1}{a} \sum_{i=2}^{n} u_{i} x_{i}^{(1)}(k+1)+\left|\hat{\varepsilon}^{(0}(k+1)\right| & k \geq k_{0} \\
\text { Next, we set } & \\
S=\sum_{k=1}^{n}\left(\hat{x}^{(0)}(k)-x^{(0)}(k)\right)^{2}
\end{array}\right.
$$

When the first order derivative of the sequence is 0 , the prediction error get the minimum value.

At this point, we can get the final prediction equation as shown below:

$$
\hat{x}_{1}^{(0)}(k+1)= \begin{cases}\frac{\left[x_{1}^{(1)}(0)-\frac{u}{a}\right]\left[1-e^{a}\right]^{-1}+\sum_{k=2}^{n} x_{1}^{(0)}(k) e^{-a(k-1)}}{\left(1-e^{a}\right)^{-2}+\sum_{k=2}^{n} e^{-2 a(k-1)}} \cdot\left(1-e^{a}\right)^{-1} e^{-a k}+\frac{u}{a} & k<k_{0} \\ \frac{\left[x_{1}^{(1)}(0)-\frac{u}{a}\right]\left[1-e^{a}\right]^{-1}+\sum_{k=2}^{n} x_{1}^{(0)}(k) e^{-a(k-1)}}{\left(1-e^{a}\right)^{-2}+\sum_{k=2}^{n} e^{-2 a(k-1)}} \cdot\left(1-e^{a}\right)^{-1} e^{-a k}+\left|\hat{\varepsilon}^{0}(k+1)\right| & k \geq k_{0}\end{cases}
$$

Where, $k=0,1, \mathrm{~L}, n-1$

After finishing the equation 11, we can get:

$$
\hat{x}_{1}^{(0)}(k+1)= \begin{cases}\frac{\left[x_{1}^{(1)}(0)-\frac{u}{a}\right]\left[1-e^{a}\right]^{-1}+\sum_{k=2}^{n} x_{1}^{(0)}(k) e^{-a(k-1)}}{\left(1-e^{a}\right)^{-2}+\sum_{k=2}^{n} e^{-2 a(k-1)}} \cdot e^{-a k} & k<k_{0} \\ \frac{\left[x_{1}^{(1)}(0)-\frac{u}{a}\right]\left[1-e^{a}\right]^{-1}+\sum_{k=-2}^{n} x_{1}^{(0)}(k) e^{-a(k-1)}}{\left(1-e^{a}\right)^{-2}+\sum_{k=2}^{n} e^{-2 a(k-1)}} \cdot e^{-a k}+\left|\hat{\varepsilon}^{0}(k+1)\right| & k \geq k_{0}\end{cases}
$$

$$
\text { Where, } k=0,1, \mathrm{~L}, n-1
$$

In Figure 2, we give the flow chart of the algorithm.

\section{EXPERIMENT AND RESULT ANALYSIS}

This paper selects the accounting data of the economic management of key universities as a key research object. The data is the unit cost of education from 2001 to 2009. Assume that all the students in the college are divided into the major of engineering cost, accounting, e-commerce, business administration, finance and graduate education. In recent years, the economic development of the country has become more stable, university education has gradually to the right track. Especially in the early 21 century, the state adjusted the enrollment policy, and the university education has completed the transition from the elite education to mass education. Therefore, the data from 2009 to 2001 are in line with the characteristics of the times. In this paper, the experiment has a certain representation, and the results of the experiment are more practical.

Initial data of the unit cost of education of universities in economics and management, as shown in Figure 3.

According to figure 3, we can see that the unit cost of education in university is increasing year by year. For this kind of approximate monotone curve, it is very suitable to use the gray model to predict. We use grey model of adaptive modified residuals to forecast the unit cost of education in 2011-2014. In this paper, according to the prediction formula 12 , the output of the prediction results are shown in Figure 4.

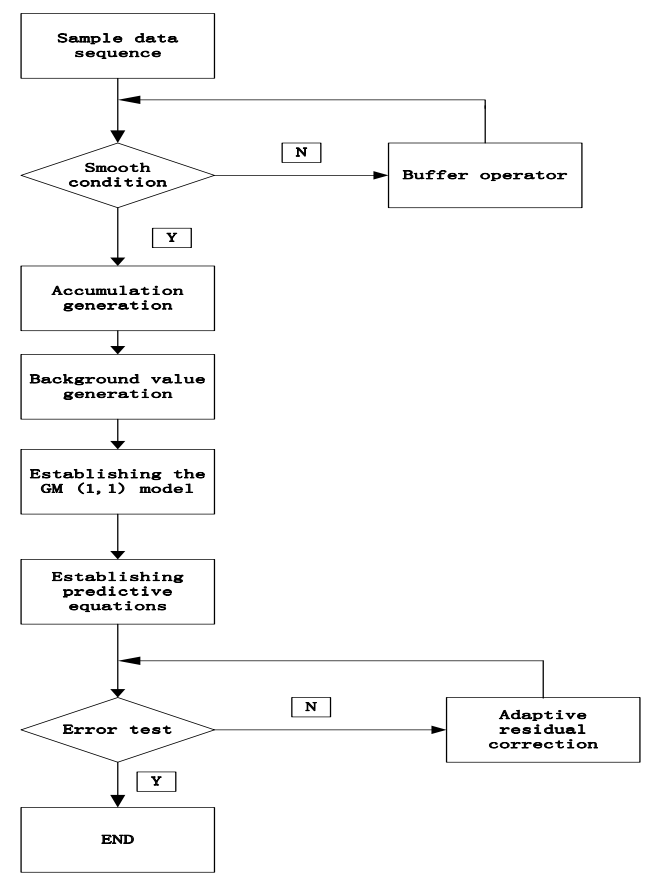

Figure 2. The flow chart of grey prediction

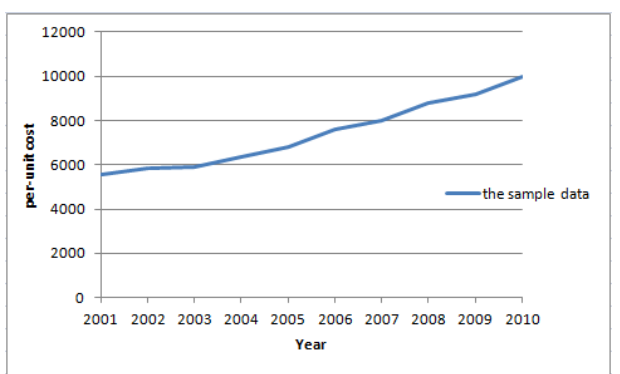

Figure 3. Sample data sequence

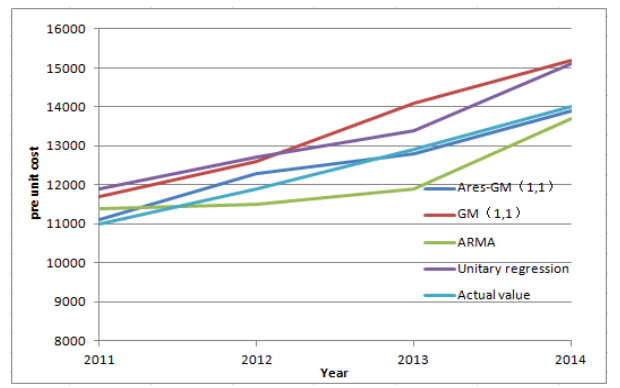

Figure 4. Comparison chart of prediction result 
The prediction values of different models in this paper are shown in figure 4 . The forecast result of the model is only for us to provide the development trends. In order to choose a suitable development model, we must consider the objective and subjective needs. The forecast results also prove that the cost of the university is increasing. According to the theory of education cost compensation, university education is an industry of increasing cost. From the situation of educational reform in the world, the rise of the cost of education has become a trend.

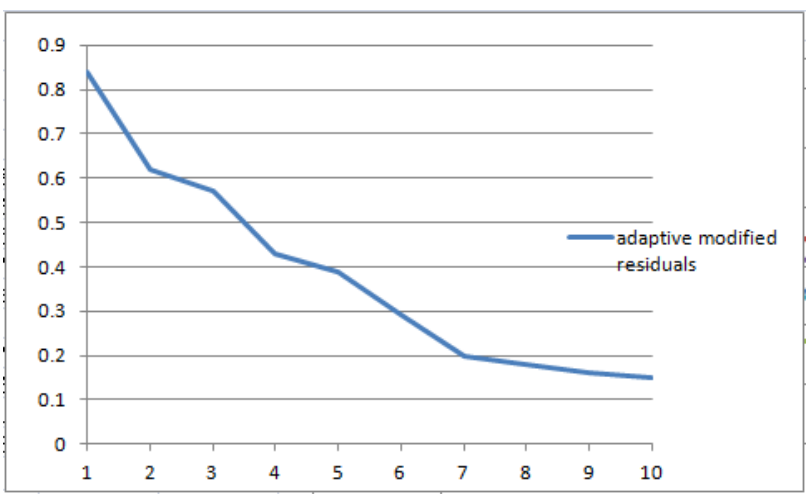

Figure 5. The variation curve of adaptive residual

It is not hard to see that the prediction model proposed in this paper can be stabilized with the increase of the number of iterations. Figure 5 shows that the residuals of this paper are convergent. From Figure 4, we can see that the forecast value of this paper is close to the true value curve, while the accuracy of other methods is lower than that in this paper. The main reason is that unitary regression method is very difficult to effectively remove the noise value in the fitting. Artificial neural network model is applied to predict the big data. Although the traditional gray forecasting model has a good prediction effect with the less data and poor information, the model still has the disadvantage that the background value is not smooth enough.

\section{CONCLUSION}

In this paper, the prediction method of the small sample, the uncertainty and the nonlinear problem of the educational cost of the university are studied. Through the research, the grey forecasting model based on grey theory is established, and the corresponding algorithm is given. The practical results show that the traditional algorithm is limited. Adopting the grey system theory to forecast is feasible. The forecast of the cost of education in university is conducive to strengthening the management of the cost of education, mining the potential of reducing the cost, improving the management level and improving the use efficiency of the funds. Through accounting and forecasting of the cost of education in university, we can make the school according to its own practice to plan the cost and quota index, so as to improve the financial system and university education cost management system. This will enable the university to carry out the correct decisionmaking, and provide support for the preparation of financial budget and long-term planning

\section{REFERENCES}

[1] John. Vaizey. The Cost of Education M. London: Allen and Unwin, 1958, 45- 63

[2] T. W. Schulte. The Economic Value of Education M. NewYork: Columbia University Press, 1963, 20- 37.

[3] E. Cohn. The Economics of Education M. Oxford: Program press, 1989, 210- 239.

[4] Wang Geng. The cost of higher education in the school of Education [J]. Accounting research, 1988 (6):17-24

[5] Yan Dawu, Wang Geng. Education cost study [J]. Education and economy, 1989 (3).

[6] Wang Shanmai. Research on education investment and production[d]. Shijiazhuang: Hebei Education Press, 1996

[7] Yuan Liansheng. Education cost measurement [M]. Beijing: Beijing Normal University press, 2000

[8] Johnes J. Measuring teaching efficiency in higher education: An application of data envelopment analysis to economics graduates from UK Universities 1993[J]. European Journal of Operational Research, 2006, (174): 443-456. http://dx.doi.org/10.1016/ j.ejor.2005.02.044

[9] Hong L. L, Lei F. L., Ma W. F... Multi-product total cost functions for higher education: The case of Chinese research universities [J]. Economics of Education Review, 2009, 28(4):505-511. http://dx.doi.org/10.1016/j.econedurev.2008.11.002

[10] Feng B. J., Li Y. X., Zhang Y. J.. Study on Construction of Education Cost of Research University in China[C].The 4rd (2012) International Conference on Financial Risk and Corporate Financial Management, Dalian, 2012:499-505.

[11] Cropper P., Cook R. Developments: Activity-Based Costing in Universities-- Five Years on [J]. Public Money \& Management, 2000, 20(2):61-68. http://dx.doi.org/10.1111/1467-9302.00213

[12] Total cost accounting management in commercial enterprises [J]. management, 2013, (5): 190-197

[13] Zhao Xiaohong, Jiao Yumei. Analysis of the cost accounting method of inquiry [J]. Chinese foreign investment, 2013, (12): 115-119

[14] Into the University of higher learning cost efficiency of [J]. Journal of Jiangxi University of Finance and Economics, 2008, (3): 102-108

[15] Peng Anchen. Empirical analysis of the allocation efficiency of graduate education resources in University [D]. Hubei: Huazhong University of Science and Technology, 2006

\section{AUTHORS}

Chao Ge, female, born in December, 1983. She obtained a Master degree in Law in 2009. At present, she works as section chief of Teaching Management Section in Humanities and Social Sciences College of Agricultural University of Hebei. Her title is Social Sciences Research Assistant. Her research field is Law. (e-mail: author@ boulder.nist.gov).

Jiaqi Xie, born in Mar, 1982. Xie obtained a Master degree in Agricultural and Forestry Economy Management in 2009. At present, Xie works as instructor at deputy section chief level in College of Economics and Trade of Agricultural University of Hebei. Xie's title is lecturer in ideological and political education. (e-mail: a 82375051@qq.com).

This work was supported in part by 2014 Philosophical and Social Sciences Research Program of Baoding City: Study on the Quality of Employment in Human Resources Market of Baoding City (Grant No. 20140220). Submitted 07 November 2015. Published as resubmitted by the authors 05 December 2015. 